Boise State University

ScholarWorks

Political Science Faculty Publications and

Presentations

Department of Political Science

$12-1-2010$

\title{
Can Community Design Build Trust? A Comparative Study of Design Factors in Boise, Idaho Neighborhoods
}

Susan G. Mason

Boise State University

\section{(c) $(1) \Theta \Theta$}




\title{
Can Community Design Build Trust? A Comparative Study of Design Factors in Boise, Idaho Neighborhoods
}

\author{
Susan Mason \\ Boise State University
}

\section{Introduction}

Social scientists have increasingly probed the alleged negative consequences of urban sprawl for neighborhoods. The frequent criticisms of urban sprawl include social stratification of communities (St. Antoine, 2007, p. 128) and the subsequent decline in social capital for individuals and communities, driven by the resulting social isolation of the urban poor (Wilson, 1996). Isolation is not solely in the domain of urban residents. Suburban residents also experience isolation where Americans concern for their private homes overrides other civic matters (Kunslter, 1998, p. 106). Sprawl is associated with increasing social segregation, social homogeneity, taking more time to commute resulting in less time with friends and neighbors, as well as disrupting community "boundedness" with large separations between work, home, and shops (Putnam 2000, p. 214).

Community design, in terms of the structure of our built environment, has gained prominence as one way to mend what ails our cities and communities. Both new urbanists (Duany, Plater-Zyberk, and Speck, 2000) and older urbanists (Jacobs, 1961) contend the antidote to what ails cities and neighborhoods suffering from the drawbacks of lower density living is the opposite: higher density living and mixed use development. New Urbanism provides more street connectivity and neighborhoods with mixed uses including public transportation, shops and offices within short blocks and more walkable distances from residences. The design creates more opportunity and places for spontaneous interactions among residents to occur that may be trivial in isolation but not so when the collective impact of the interactions are taken into consideration (Jacobs, 1961, p. 56). More recent studies found neighborhood designs that require car use inhibit social ties among neighbors (Freeman, 2001, p. 76). The potential of neighborhood design increases in the face of other known factors that can inhibit social capital production such as the effect of community heterogeneity on trust.

Studies abound on the connection between greater community heterogeneity in terms of diversity in languages, races, and income inequality being negatively associated with trust at both the individual and societal levels. Costa and Kahn (2003, p. 106) found that for individuals between 24 and 54 years of age, economic "heterogeneity explains anywhere from one-third to almost all of the declines in volunteering, membership and trust." Hero (2003) found racial and ethnic diversity are negatively related to social capital. He identified increased social capital in the community at the aggregate level occurs primarily with economic equality in white populations (p. 120). At the neighborhood level Leigh (2006, p. 279) reported more trust in wealthy neighborhoods and less trust in ethnically or linguistically diverse neighborhoods. In a study of 59 countries, Leigh (2006b, p. 124) also found that ethnic diversity and income inequality lowered trust. In contrast to previous findings in the U.S. and Australian neighborhoods, Leigh found that inequality rather than ethnic diversity played a larger role in reducing trust. (See Coffe and Geys, (2006) for a comprehensive review of more recent studies of community heterogeneity and social capital at the individual, municipal, and country level).

Rothstein and Uslaner (2005) report equality promotes trust. They contend, at the country level, the best way to promote trust is through universal social programs that redistribute resources to increase equality. Rothstein and Uslaner (pp. 10-13) found low trust and social capital inhibit government action to increase equality. The implications extend beyond the country level and could be considered at the neighborhood level where community design can foster greater social capital production by affording people increased opportunities to interact and build trust. Increased interaction enhances trust allowing design to overcome outcomes associated with income inequality such as social isolation, less civic participation, and disparity in opportunities among citizens of different income categories. Finding ways to increase trust may be especially important in free-market societies such as the U.S. which are much less likely to provide universal social programs than countries like Sweden.

As Christen (2009, p. 32) notes, scholars such as Falconer Al-Hindi and Till (2001) and Brain (2005) contend the influence of New Urbanism demands more understanding and empirical research from both the practical and theoretical standpoints. This study takes a step in that direction by exploring two relationships with community 
design and trust. First, is one benefit of a few of the underlying concepts of New Urbanism design that are found in Traditional Designed Neighborhoods (TND) is that they also build trust? ${ }^{1}$ Second, can these specific design concepts overcome one undesirable feature of cities: the deleterious effect of one measure of community heterogeneity, income inequality, on trust? This study only examines a very small number of and specific design factors that promote a few of the principles of New Urbanism and that are found in TND such as walkability, connectivity, and quality urban design. The findings reveal that a few of the specific community design features studied can build trust, but there is no evidence that design moderates the effect of income inequality on trust.

The article starts with a review of the literature on community design's potential to influence positively social interaction in general and social capital specifically. Then the discussion turns to the importance of examining design at the neighborhood level. Next the hypothesis, research design, and methods are discussed, followed by the results of the analysis. In the conclusion policy implications and directions for future research on community design are discussed.

\section{Literature Review Community Design and Social Interaction}

New Urbanism design advocates contend neighborhood design elements that increase pedestrian traffic and encourage social interaction foster community cohesion. Is it possible, then, that some New Urbanism design features can mediate problems or foster the resolution to social phenomenon that past efforts have not? Macintyre and Ellaway (2000) maintain the physical environment, including the built environment, has a profound influence on the way people think, feel, and act. Riger and Lavrakas (1981) found community attachment is both a function of individual and environmental factors. Similar to Freeman (2001), Naser and Julian (1995) documented that community design which permits more face to face interaction generates a greater sense of community. Additionally, Lund (2003, p. 428) specifically found, "people who walk around their neighborhood are more likely to interact with and form relationships with their neighbors." Lund also determined design that locates pedestrian streetscapes, parks and retail within a neighborhood increases the likelihood of neighbor interaction. Leyden (2002) considered neighborhood type in Galway City, Ireland, choosing a high growth community with varied neighborhoods including a new urban-style design and classic suburban design and found political participation was positively associated with design. (For a thorough recount of the studies examining both design and environmental influences on sense of community see Talen, 1999).

In one study of a New Urbanism design community, Orenco Station, (in Portland, Oregon) residents' responses were compared to responses from residents in a long established ethnically diverse part of downtown Portland as well as residents in a more established traditional suburban section of the city. The findings demonstrated New Urbanism design's success in generating trust and goodwill among neighbors but the design features did not produce bridging social capital with the wider city (Podobnik 2002, pp. 249, 252). Additionally, Plas and Lewis (1996) documented in the prototype New Urbanism community of Seaside, Florida an increasing sense of community. In short, evidence of New Urbanism design's desirability and potential to help with physical, environmental and social concerns facing individuals and communities exists. Yet, only rarely (e.g., Podobnik, 2002) has community design been considered as a factor that might help overcome the problems that inequality can cause for the creation of social capital in our neighborhoods.

\section{Community design, inequality and social capital}

Rohe (2009) highlights the changes in planning with regard to neighborhood design over the past 100 years. He notes that the most recent attention has been paid to Planned Unit Developments (PUD), Traditional Neighborhood Design (TND) and Transit Oriented Development (TOD) where the later two encourage walkability, mass transit, social interaction and social cohesion. Although these factors are seemingly more important than ever given the growing concern with greenhouse gas emission and climate change, evidence of the value of community design to create the places deemed most beneficial wanes. In fact Rohe (2009, p. 226) notes:

\footnotetext{
${ }^{1}$ The principles or primary concepts of New Urbanism are 10 factors that can be applied to communities to promote, walkability, connectivity, mixed use and diversity, mixed housing, quality architecture and urban design, increased density, green transportation, sustainability and quality of life (New Urbanism, 2010).
} 
Although the research on TND and TOD is still sparse and often based on a small number of case studies it has not supported the claims of its proponents. For example, studies have found that TND residents do not report a greater sense of community than do residents of traditional neighborhood subdivisions (Brown and Cooper 2001; Nassar 2003).

Bramely and Power (2009, p. 46) find that community design has an impact on neighborhoods. Specifically, they report that dense/compact urban forms tend to worsen neighborhood problems especially where there are concentrations of poverty and renting of housing. At the same time denser communities are more likely to provide access to services. Yang $(2009$, p. 307) also finds differences among communities on satisfaction with outcomes by the density of neighborhoods. Yang notes that in Portland density and mixed use are associated with great neighborhood satisfaction but he finds also the converse is true in Charlotte, North Carolina. Of note, once Yang examines data at the block level he finds that single family detached housing is associated with higher levels of neighborhood satisfaction in both Portland and Charlotte. This suggests there may be trade-off in terms of policy with regard to urban forms and that no one design is potentially the answer for most of the people most of the time.

All the same the public perception is that TND is desirable. Handy $(2008, p .219)$ finds through surveys conducted in 2003 and 2005 that support TND communities grew to the point that it could be characterized as "strong, widespread and growing". Clearly the debate on community design's potential to influence outcomes in our neighborhoods is ongoing.

Unlike the proponents of New Urbanism design, St. Antoine (2007, p.142) contends, "The rhetoric [of New Urbanism] attracts middle class home buyers and addresses issues related to identity and alienation in suburbia but it fails to correct for the material consequences of suburban sprawl". For St. Antoine (p.141) the material consequences of suburban sprawl are "environmental problems, social isolation, and economic and racial homogeneity." To this point, Podobnik's (2002, p.253) study demonstrates a moderately exclusionary attitude of Orenco Station residents who indicated they moved to the neighborhood because they wanted to live in a highdensity social interactive place. Yet, in reality, two-thirds of occupants were happy with the existing diversity (95 percent white) and two-thirds indicated "no" outright or had significant reservations about building affordable houses designed for people with lower incomes in the neighborhood. Podobnik's study fleshes out what people say from what their real preferences may be. Podobnik's study takes into account individual preferences and finds these preferences temper the potential influence of community design. Even though individual reported preferences may not be influenced by design, the glue of social capital is place based extending the potential influence of community design on society.

Much has been written on the evolution of the concept of social capital and its bonding and bridging properties (Putnam 2000, p 22; Paxton 1999; Agnitsch, Flora, and Ryan, 2006; Bridger \& Alter, 2006). Measures of social capital have been generated at many levels: individual, neighborhood, municipal, and national. It is now widely accepted that dense networks of social ties and the associated norms generate the trust and reciprocity that are essential for social capital (Coffe and Geys, 2005). Bridger and Alter (2006, p. 8) find that social capital has linkages to place and builds community through mutuality of interests. They note that, "To see why this is so, it is important to understand that networks, norms, and trust are context dependent. Social networks are not free floating; they are bounded by space and time." The fact that the development of trust is context specific makes it possible to conceive that community design could have a positive impact on trust and help create social capital.

\section{Neighborhoods: Context for Community Design}

Garde (2004) determined most New Urbanist projects (promoting sustainable development and using smart growth principles) occur at the neighborhood as opposed to the regional level. Song (2005) similarly recommends and conducts research at the neighborhood level rather than the city or metropolitan area level to increase precision of understanding of urban development patterns. Song (2005, p. 247) also notes that studies such as Galster et al.'s (2001) focus on "one and one-half mile grids [that] are probably imperceptible to policy makers". Subsequently, the principle of design will be embodied at the neighborhood public policy level in this study. If public policy can be used to foster designs that create strong communities by building trust for the production of social capital, then community design's potential to overcome problems of inequality for society can also be considered.

This study extends the scholarship on social capital and community heterogeneity in two ways. First, the analysis examines individual level trust of residents in 34 City of Boise neighborhoods because trust is fundamental to the creation of bonding social capital at the individual level in neighborhoods. Social interactions are understood to foster trust. Trust of individuals at the neighborhood level can in turn create a sense of community that results 
from the production of social capital or social cohesion generated by the trust. Second, community design is a largely overlooked factor that may moderate the effect of income inequality, one measure of community heterogeneity. If evidence exists that community design can provide a mechanism to overcome factors such as property devaluation or negative stereotypes then community design's potential for rendering mixed use neighborhoods and neighborhoods with sustainable affordable housing can be realized. In short, this study tests the suppositions that community design can build trust as well as moderate the deleterious effects of income inequality on the creation of trust.

\section{Hypotheses}

Community design is expected to positively affect trust and moderate the impact of income inequality on trust. Community design is operationalized to include street design, sidewalks and open space within a walkable distance of one's home. New Urbanism design contends the benefits of human scale within neighborhoods that have mixed uses, amenities such as parks in walkable distances, streets that provide connectivity and supplying multiple pedestrian and vehicular routes with sidewalks and grid-iron patterns create more amenable communities. These attributes balance automobile and pedestrian needs, create pleasurable walkable environments and save resources (Steuteville and Langdon, 2003, pp.1-2 to 1-3). One element of the physical design of New Urbanism is to encourage social cohesion (Steuteville and Langdon, p.19-7). New Urbanists recognize that an attractive design does not alone create a vibrant community (Steuteville and Langdon, p. 19-7). Yet, is it possible that some New Urbanism design elements foster the trust that generates the social cohesion the design encourages? The previously noted theories of Jacobs (1961) and evidence by Macintyre and Ellaway (2000), Riger and Lavrakas (1981), Freeman (2001), Nasser and Julian (1995), and Lund (2003) all suggest design can influence social cohesion and Podobnik (2002) specifically found it can generate trust and goodwill. Yet, as evidenced by the findings of Bramley and Power (2009), Rohe (2009), and Yang (2008) on the value of TND and design that increases density, walkability and a sense of community the outcomes are mixed at best. Even in light of this, Handy (2008) observes that the popularity of these designs is growing. Subsequently, the features and outcomes of community design warrant further exploration.

Neighborhood street designs have been categorized as traditional with a straight line grid-iron pattern to non-linear designs. The non-linear patterns include the more modern subdivisions found today with curved streets that wander through housing developments and subdivision punctuated with cul-de-sacs (Mason and Fredericksen, 2009; Lund, 2003). This study hypothesizes people who live on streets designed in the traditional vein (pre 1945) with a gridiron pattern and alleys will rate higher on trust which can impact social capital at the neighborhood level. Moreover, people who live on curvilinear streets are expected to rate higher on trust than people living cul-de-sacs street designs. Additionally, people that report the design features of proximity to parks and open space as well as having a sidewalk are hypothesized to report greater trust.

\section{Methodology}

Oliver, in his 1999 article on economic segregation and civic participation, laments that most comparisons do not take into account contextual factors. ${ }^{2}$ Due to a lack of data about both individuals and their place of residence, studies of suburban areas and cities "are based on either case studies or particular places or crude dichotomous comparison between central cities and suburbs" (p. 187). This study overcomes the shortfalls of previous studies that Oliver notes by making use of individual data and contextual factors to evaluate the role that community design plays in building trust and moderating the effects of income heterogeneity on trust. Data for individuals living in 34 City of Boise neighborhoods were drawn from geographic information systems (GIS) using demographic data from 147 census block groups aggregated to the 34 formally recognized Boise neighborhoods to measure individual income inequality among neighborhood residents (Geolytics, 2000; and City of Boise, 2006). In some cases portions of block group data were aggregated using the percentage of the block group contained in the neighborhood boundary. An assumption that the data were evenly distributed was made when a portion of a block group included the neighborhood area.

Specific individual level data were drawn from a survey. The survey asked specific questions about amenities such as having a park or open space near ones home and the frequency of walking to it, number of neighbors known on first name basis, number of neighbors consider as a friend are examples of some of the more

\footnotetext{
${ }^{2}$ One exception is Dekker and Van Kempen's (2008) study that compares individuals in different countries and demonstrated both individual and neighborhood contexts account for variation in civic participation.
} 
general questions. The survey also included a series of questions on neighborhood perceptions. These questions included whether the respondent considered the neighborhood to be close knit, the people in the neighborhood could be trusted, that people in the neighborhood share the same values, and if there was a willingness to help their neighbors. Questions on general demographics such as age and income were also asked.

To collect the survey data a mailing list was generated for residents in 34 City of Boise neighborhoods. ${ }^{3}$ Random samples of 54 residents were drawn for each neighborhood. Ultimately, 1,835 randomly sampled residences across 34 recognized neighborhoods in the City of Boise were sent the survey. Following Dillman's (2007) total design method for survey research the returns from the first mailing, a second mailing to the residences with unreturned surveys, and a follow-up phone call to the residences to encourage survey returns produced a response rate of 39 percent with 721 surveys returned.

\section{Dependent variable}

Although many factors contribute to social capital production, trust remains the cornerstone. This research focuses on the way community design can increase trust. Informal neighborhood networks are a form of bonding social capital which creates "a place-based community (neighborhood) with informal networked relationships within the neighborhood" (Brisson and Usher, 2007, p. 67). This study uses a measure of trust also used in Brisson and Usher's (2007) study. The measure asks respondents how strongly they agree or disagree on a five point scale that "people in this neighborhood can be trusted." 4 The measure of trust was originally developed and tested in the Project on Human Development in Chicago Neighborhoods (PHDCN) to create an index for social cohesion and trust (Sampson, Raudenbush, and Earls, 1997). The focus in this study is on the particular question of trust rather than an index of factors that contribute to social capital. Using a single measure generates more insight into the way design specifically contributes to social capital production in terms of generating trust.

\section{Independent variables}

The independent variables at the neighborhood level include street design, presence of sidewalks, and whether the residence is in walking distance of a park or open space. The streets are categorized as traditional, curvilinear, and cul-de-sac as a further refinement from the aggregated neighborhood level grouping previously used by Mason and Fredericksen (2009). Mason and Fredericksen classified entire neighborhoods as being in the traditional design, contemporary (referring to either curvilinear or cul-de-sac) or transitional referring to neighborhoods that had a mix of these street designs. As previously noted, the traditional design street was typically established pre-WWII and is typified by grid-patterned, smaller lots, narrower streets, and alley ways. The curvilinear street and cul-de-sacs are typically found in more contemporary subdivisions with smaller streets connecting pods of housing. (See Figures 1 and 2 for an illustration of the street designs). A respondent was only listed as living in cul-de-sac designed street if the respondent actually lived on the street terminating with a cul-de-sac. ${ }^{5}$ This is unlike respondents on curvilinear or grid streets that may exit their streets (and homes if you consider the alleys associated with grid streets pattern) in more than one manner. As such categorization of each survey response by street design reflects the neighborhood street pattern in the block where the respondent lives. Because research at the street level by Gans (1961) and Mayo $(1979 ; 1979 b)$ specifically indicated that cul-de-sacs do not promote greater neighborliness, cul-de-sacs are examined separately from curvilinear streets. The distinct design of cul-de-sacs with only one outlet and the circular nature of the street design is an added reason they are separated out from curvilinear in this study. Scholars such as Galster et al. (2001); Lund (2003); Talen (2003) have highlighted the importance of appropriate measurement and the relevance of street design in studies. As such this study endeavors to provide the appropriate specificity to better understand the findings.

To consider the effect of merely having sidewalks as opposed to the street design of the neighborhood, the presence of a sidewalk on the resident's parcel of land was also considered. Finally, the residents' yes or no response to the survey question, "Thinking about where you live, is there a park or open space such as neighborhood garden or access to the foothills or greenbelt within walking distance of your residence?" was also considered as a design factor that could potentially contribute to creating trust that builds social capital.

[Insert Figure 1 and 2 about Here]

\footnotetext{
${ }^{3}$ The City of Boise's policy makers and planning professionals formally recognize the 34 neighborhoods as being distinct social/political units. The neighborhood associations' geographic boundaries are developed by residents and registered with the City. The City screens applications for new neighborhood associations to avoid conflicting boundaries or other issues with existing neighborhood associations. These neighborhoods have a common identity and are commonly used to indicate both neighborhoods and locations within the city.

${ }^{4}$ The seven point scale on the survey was reduced to a five point scale for analysis and in keeping with previous research using this measure.

${ }^{5}$ This was made possible because the survey responses were geocoded by address.
} 


\section{Control Variables}

This study focuses on trust and distinguishes design from the contextual factors of neighborhood income, length of residence, individual's age, gender, marital status, education, household structure, and homeownership as seen in Table 1. Brisson and Usher (2007, p. 66) in their study noted that both income and length of residence are commonly associated with social capital production. Additionally, research by Gans (1961) and Mayo (1979; 1979b) specifically found that there are other cultural factors such as homogeneity and contextual factors such as length of residence that contribute to social life rather than street design. Furthermore, Freeman (2001, p. 71) suggests that income may play a role noting that others have found poorer neighborhoods have fewer social ties. Communities with low income associate with civic apathy (Edwards and Foley, 1997) and communities with similarly low or high incomes associate with less civic participation (Oliver, 1999). As such income is used as a control variable specifically; individual self-reported 2006 household income was included in the model. Additionally, the variable measuring income inequality varies from 0 to 222,245 where higher values reflect higher levels income inequality. ${ }^{6}$ The mean rate of income inequality is 9,367 . Although studies in the past suggest length of residence increases trust (Brisson and Usher, 2007; Mayo 1979, 1979b, and Mayo 1961) a more recent study by Hur and Morrow-Jones (2008, p. 632) did not find a link between neighborhood satisfaction and length of residence if one is satisfied with one's neighborhood but did find a positive relationship if one lived in an unsatisfactory neighborhoods (i.e., neighborhood with higher levels of safety and social problems). The remaining individual level control variables include an individual's age, gender, marital status, education, household structure, and homeownership. Sampson, Raudenbush, and Earls (1997, p. 921) found that length of homeownership is positively associated with community attachment. As such, factors such as age and length of residence provide potential correlations with trust. Additionally, Campbell and Lee (1992) find that being female, married, having children and more education are positively associated with having greater neighborhood networks and are therefore also included as control variables.

\section{Descriptive Statistics}

In examining the independent variables in this study 17 percent of the responses were from people living on traditional design streets. Sixty-seven percent were curvilinear and 16 percent cul-de-sac design. Eighty percent of the traditional designed street respondents had sidewalks compared to 50 and 67 percent of respondents living on curvilinear and cul-de-sac designed streets, respectively. Additionally, the residents' yes or no response to the survey question, "Thinking about where you live, is there a park or open space such as neighborhood garden or access to the foothills or greenbelt within walking distance of your residence?" was also considered as a design factor that could potentially contribute to creating trust that builds social capital. Eighty-one percent of the respondents answered yes to this question with 92 percent of respondents on traditional designed streets as compared to 80 and 78 percent on curvilinear or cul-de-sac designed streets, respectively.

The survey respondents' statistics for the control variables compared to the aggregated census data for the City of Boise neighborhoods reasonably well where 61 percent of the population was female, 28 percent of the population reported having children under 18 in the household, 30 percent had a bachelor's degree and 66 percent were homeowners. ${ }^{7}$ In addition to homeowners being over-represented in the sample, individuals with highest incomes $(\$ 100,000$ or more) were more likely to respond to the survey $(32 \%)$ than all other income groups. In comparison, the percentage of people in the neighborhoods in the highest income category was only 11 percent. Residents in the lowest income (less than $\$ 20,000$ ) were the least likely $(5 \%)$ to respond to the mail survey. The number of persons in this income category was substantially smaller than the census estimates of 18 percent for the neighborhoods. The data were weighted by income, working on the assumption that people who earn less income are more likely to rent than own their home, and this would adjust for the smaller percentage of people renting as compared owning their home in the study as well. This study intentionally did not include race in the model. Since

\footnotetext{
${ }^{6}$ Using a similar method to Coffe and Geys (2006, p. 1060) to calculate income inequality I take the fraction of the difference in reported household income and the median neighborhood income where inequality is calculated as [(Individual income - Median income of neighborhood)/ Median of Neighborhood]. The value is also included in the model as squared because Oliver (1999, p. 198) finds income has a curvilinear relationship with one measure of social capital: civic participation.

${ }^{7}$ One explanation for the difference in respondents to the population in terms homeowner rates may be due to the fact the final mailing list was drawn from parcel addresses without unit designations and run against the U.S. post office list of valid mailing addresses. Many apartment and rental units have apartment numbers or unit designations of $\mathrm{A}, \mathrm{B}$ or $\mathrm{C}$ in addition to the address so there may have been unintentional over sampling of homeowners.
} 
the U.S. Census reported 92.2 percent of the City of Boise's population was white and only 4.5 percent Hispanic, the lack of diversity offered a unique control on community heterogeneity (U.S. Census, 2008). The survey data for the City of Boise neighborhoods reflects 97 percent of the respondents were white residents and only 2 percent Hispanic (See Table 1 for descriptive statistics of all measures used the analyses).

[Insert Table 1 about Here]

Finally, any comparison study on individual behavior must control for self selection in some way. Anova analysis was conducted to determine statistically significant variances in the likelihood that residents live in neighborhoods with people more like themselves than not, thus making it more likely that they trust one another. The anova analysis, to test for this type of self-selection, revealed no statistically significant differences at the 95 percent confidence level in the mean of the variable about individual's values by street design. The boxplot in Figure 3 illustrates the similar variation by street design in response to the reverse coded survey question, "People in this neighborhood do not share the same values."

[Insert Figure 3 about Here]

\section{Logistic regression models}

Two ordered logistic regression models were estimated to assess the impact of three neighborhood design factors: street design; sidewalks; and parks on trust. Additionally, the analysis examines whether these design features also moderate the influence of income inequality on trust while controlling for the previously described socioeconomic and demographic factors. The odds ratios in Table 2 indicate the likelihood of change on trust for each statistically significant independent variable. An odds ratio greater than one indicates an increased likelihood that a one unit change in the independent variable increases the odds of reporting people in the neighborhood can be trusted by one unit on the scale of one to five. An odds ratio of less than one indicates the decrease in the odds for each one-unit change in the independent variable. A negative sign before the odds ratio indicates that an increase in the independent variable by one unit would decrease the dependent variable by one minus the odds ratio.

\section{Results}

The results in Table 2 reveal five significant variables for the relationships between the non-design control variables and trust. For every year older one becomes there was a 3 percent increase in the likelihood the resident would move up on the scale from one to five indicating that people in their neighborhood can be trusted. For every additional child living at home this increased the likelihood of reported trust by 21 percent and being female increased the likelihood of reported trust by 48 percent. Unexpectedly, being a homeowner reduces the degree of reported trust in this model by the likelihood of 180 percent. Finally, income inequality was negatively related to trust as anticipated. For every 10,000 increase in the inequality measure the likelihood of reporting trust decreased by 71 percent.

[Insert Table 2 about Here]

The full model also seen in Table 2 reveals that street design, sidewalks, and parks all positively affected reported trust. The cul-de-sac street design was significantly different than the reference category curvilinear and increased the likelihood of reporting trust by 75 percent. In additional explorations, street design was run with each category as a reference. Cul-de-sac was different from curvilinear streets but neither was statistically different from traditional design streets. Living on a cul-de-sac was positively associated with trust while living on curvilinear street was negatively associated with trust. The presence of sidewalks also increased trust by 63 percent. The findings also revealed an increase in trust for people who indicated a park or open space was within walking distance of their home. These respondents were 107 percent more likely to increase their rating on trusting their neighbors. All the same control variables remained significant in the full model. The impact of age remained unchanged when design features were also considered. Having a greater number of children was also associated with an increased likelihood of reported trust when the community design features were included in the model. For every additional child in the household under 18 there was a 29 percent increase in the likelihood of the individual reporting people can be trusted in the neighborhood. This was a 8 percent increase over the former model. Being female increased the likelihood of trust in the neighborhood by 5 percent to an overall 53 percent increase in the likelihood of reported trust in the full model. Homeownership caused a greater decrease in the likelihood by an additional 8 percent or a total 188 percent decrease in the likelihood in reported trust of others in the neighborhood. Finally, the effect of income inequality was statistically significant in the full model to demonstrate an 85 percent likelihood that an increase in income inequality by 10,000 points decreases trust when also considering these design factors. 
To further augment the findings in light of the uneven variation among respondents by street design t-test results with unequal variance were run. As seen in Table 3 the t-tests reveal no differences among the respondents on traditional and curvilinear blocks in terms of trust. Yet, respondents living on cul-de-sac or curvilinear style streets demonstrated statistically significant differences in terms of their effect on trust in their neighbors. T-tests also indicated statistically significant differences in mean income by street design. The traditional street design respondents had a mean income of $\$ 51,518$ compared to $\$ 64,419$ and $\$ 73,738$ for curvilinear and cul-de-sac respondents, respectively. T-test results were statistically significant in the mean inequality scores with the greatest inequality being among respondents from traditional designed neighborhoods 22,590 followed then by curvilinear at 7,008 and the least inequality was found among the respondents from the cul-de-sac design streets with a value of 4,699. Respondents living in traditional design streets face both the lowest incomes and more income inequality than the other two types of street design. After controlling both design and income inequality in the regression the difference between traditional and more contemporary street design goes away. The cul-de-sac streets report a statistically significant greater mean number of sidewalks than curvilinear designed streets. The only statistically significantly differences in terms of parks occur when compared to traditional design streets which had a higher mean. In summary, traditional design streets have the greatest reported amounts of sidewalks and parks as well as the most inequality, and less income than either of the other two neighborhood designs. This finding supports the logistic regressions outcome on trust and that design factors such as sidewalks and parks, increase reported trust even in the face of income inequality. Contrary to the hypothesized relationship between traditional street design and trust the relationship was not statistically significant in the full model. Additionally, there was no evidence that design factors moderate the effect of income inequality differences in neighborhoods either. Furthermore, cul-de-sac streets were positively associated with increased likelihood of trust and curvilinear designed streets were negatively associated with trust.

[Insert Table 3 about Here]

\section{Conclusions}

First, these results support Hero (2003), Leigh (2006; 2006b), Coffe and Geys (2005), Rothstein and Uslaner (2005), and Costa and Kahn's (2003) findings that income inequality is negatively related to trust. Community design can increase trust but there is no evidence that design directly moderates the negative impact of income inequality on trust. The findings reveal street design, sidewalks as well as parks and open space can increase trust. In contrast to other studies, homeownership and length of residence did not increase trust. One possible explanation stems from the rapid population growth Boise, Idaho was experiencing. New entrants that bought homes may not have had the time to interact yet with their neighbors. The insignificance of length of residence might also be related to the fact that homeownership, although statistically significant was negatively related to trust. As the population increased in Boise, infill housing in established neighborhoods surged. The new entrants may have detracted from the long time residents' sense of trust about their neighbors as the new residential development changed the look of the neighborhood and increased the diversity in housing stock in the neighborhood. Long time residents may have experienced an influx of new and sometimes different neighbors in terms of race or income than would have moved to the area previously. Of note, Hur and Morrow-Jones (2008) in their study on neighborhoods similarly found no connection between length of residence and residents' neighborhood satisfaction in satisfactory neighborhoods.

The study also supported Campbell and Lee's (1992) findings on being female and household structure with children being associated with greater neighborhood cohesion where both factors increased the likelihood of reported trust. The fact that the odds ratios increased for women and households with greater numbers of children in conjunction with design factors suggests that these specific design features can increase trust. It may be as noted previously, places such as cul-de-sac streets and parks where adults with children can congregate and interact provide a mechanism to build more trust in the neighborhood.

Unlike the results of Gans (1961) study and the two studies Mayo $(1979,1979 b)$ conducted this study found that cul-de-sac street design played a role in fostering trust. Noteworthy is the fact that the respondents living on cul-de-sac design streets were positively associated with trust while curvilinear street design was negatively related to trust. Additionally analysis revealed no multi-collinearity between income and cul-de-sac street design or even curvilinear streets and the fact that living in a cul-de-sac was carefully articulated from a curvilinear street the effect in this model must be attributed to cul-de-sac and curvilinear street design as there were statistically significantly different from one another with regard to their impact on trust. Furthermore, Table 3 provides evidence that even though only $16 \%$ of the respondents lived on cul-de-sac designed streets and $67 \%$ lived on the curvilinear, there was an effect on trust for cul-de-sac and curvilinear streets but not traditional designed streets. Cul-de-sac 
design is unique in that it has one outlet. This captures the repeat trips and the resulting greater likelihood to know neighbors that must pass by both to enter and leave there homes. Complimented with its circular design this may increase the frequency of contact with neighbors. This finding actually supports Freeman (2001) and Nasar and Julian (1995) findings on community design which permits more face to face interaction generates a greater sense of community. Even though the findings for the cul-de-sacs are somewhat in contrast to New Urbanist design principles and TND when considering connectivity and the preference for using a grid-iron pattern of streets to promote that connectivity, the findings suggest street design and other design features such as sidewalks, parks and open space which foster repeat interactions can affect trust.

The prevalence of sidewalks promotes trust as other studies also suggest, but not to the degree that the culde-sac streets or access to parks and open spaces appear to do. Although Lund (2003) finds walking around ones neighborhood increases the likelihood of interaction she also noted that community design that incorporated mixed use increased the likelihood of that someone would walk around their neighborhood. The finding here provides some support for Lund's findings as in this case it may be that sidewalks unlike a destination may not provide as great of an opportunity for meaningful interaction to build trust. Simply having a sidewalk may not correlate with sidewalk use. Society may have become so automobile dependent that sidewalks that exist go unused as Freeman (2001) finds. Alternatively, another explanation may be that walking in the neighborhood does not afford enough meaningful interaction to build trust the way repeated interaction of passing in cul-de-sac or spending time in a public open space can. Yet more research would need to be conducted to truly test this last idea.

Community design did not increase the impact of age on increasing the likelihood of trust. This further reaffirms Campbell and Lees' (1992) finding that personal attributes can be directly associated to the likelihood of individuals to engage in neighborhood networks. In short, community design can influence some of us in some ways but not necessarily all of us in all ways as Yang (2008) also determined. It appears community design can indeed influence social life but not necessarily by the grid pattern street design concepts that promote connectivity. It is powerful information to suggest that local governments can influence the outcomes in their communities through zoning for streets, sidewalks and parks even if municipalities cannot change the economic stratification or social composition in their communities. In short, the findings suggest that the type of space created has the potential to help build community. Although more parks and open space may be one mechanism to build trust and in turn bonding social capital with neighbors, there may be other design features to explore as well.

In conclusion, the findings suggest community design has much to offer in terms of building trust even if design cannot overcome the issues of income inequality. The possibilities for design extend well beyond the boundaries of the fast growing relatively homogenous neighborhoods in the City of Boise. The findings suggest new possibilities for cities trying to get ahead of the growth curve or communities that want to put in place new policies and zoning to help build trust and in turn social capital in their neighborhoods. Older cities trying to revitalize their neighborhoods are also in a position to create policies that incorporate beneficial elements of community design such as safe parks, plazas or other public spaces as well as sidewalks which can positively impact trust and social capital even if they cannot change their roads. The potential benefits extend to the building and design of public housing and urban renewal districts, regardless of their current level of racial and economic diversity. Achieving these outcomes may involve creating pathways of connectivity between units or creating a community complex rather than an open air park in some instances. Most importantly though, in an era where planners and citizens can participate in the design of their communities this research points to specific ways to build healthier communities rather than relying on rhetoric or conventional wisdom as a guide. Clearly more research on the actual ways cul-desacs designed streets, sidewalks, walking, parks and open space contribute to increased trust could better isolate specifically the way these design features contribute to building stronger communities. Direct measures of social interaction would also be valuable for future research. Understanding more about the way open space and community design affect the quality of life may be particularly important for our aging populations as Sugiyama and Thompson (2009) noted in their study. The preliminary evidence presented here suggests some specific elements that underlie some of the urban design principles promoted for creating sustainable communities that community design has to offer for building trust in communities.

Finally, additional research that examines retail or other public spaces such as transit oriented development (TOD) where commuters may find themselves with the opportunity to interact repeatedly with the same people could prove useful as well. It is possible that while waiting for the metro and ducking into the neighborhood market week after week provides enough opportunity to interact with people across communities demonstrating yet another way built form is conducive to building trust. The potential to learn more about fostering trust and building bridging social capital which crosses communities is vast. Future research on TOD districts and trust could help our understanding of the much less studied bridging social capital that extends beyond the neighborhood or city block and crosses communities. Knowing more about bridging social capital could also go a long way to helping us 
understand why some communities are more likely to engage in collective action than others. The potential for community design to play an active role in shaping our communities continues to be realized. The findings provide evidence that the specifics of community design are worth exploring in more detail.

\section{References}

Agnitsch, K., Flora, J., \& Ryan, V. (2006) Bonding and Bridging Social Capital: The Interactive Affects on Community Action. Community Development: Journal of the Community Development Society 37, 36-51.

Brain, D. (2005) From good neighborhood to sustainable cities: Social science and the social agenda of new urbanism. International Regional Science Review 28 (2), 217-238.

Bramely G. and Power, S. (2009) Urban form and social sustainability: the role of density and housing type. Environment and Planning B: Planning and Design 36, 30-48.

Bridger, J. C. and Alter, T. R. (2006) Place, Community Development and Social Capital Community Development: Journal of the Community Development Society 37, 5-18.

Brisson C. and Usher, C. L. (2007) The Effects of Informal Neighborhood Social Bounding Capital and Neighborhood Context on Homeownership for Families living in Poverty. Journal of Urban Affairs 29, 66-75.

Christens, B. (2009) Suburban Decentralization and the New Urbanism: A pragmatic Inquiry into Value-Based Claims. Journal of Architectural and Planning Research 26 (1), 30-43.

City of Boise. (2006) GIS Data. Planning and Development Services. Boise, ID.

Campbell K. E and Lee B. E. (1992). Sources of Personal Neighbor Networks: Social

Integration, Need, or Time? Social Forces 70, (4) 1077-1100.

Coffe, H. and Geys, B. (2006) Community Heterogeneity: A Burden for the Creation of Social Capital? Social Science Quarterly 87, 1053-1071.

Coffe, H. and Geys, B. (2005) Institutional Performance and Social Capital: An Application to the Local Government Level. Journal of Urban Affairs 27, 485-501.

Community Planning Association of Southwest Idaho. (2006) Transportation Analysis Zones. [GIS data] Boise, ID.

Costa, D. L., and Kahn, K. (2003) Civic engagement and community heterogeneity: An economist's perspective. Perspectives on Politics 1, 103-111. 
This is an author-produced, peer-reviewed version of this article. The final, definitive version of this document can be found online at Cities, published by Elsevier. Copyright restrictions may apply. doi: 10.1016/j.cities.2010.07.003

Dekker, K. and Van Kempen, R. (2008) Places and Participation: Comparing Resident Participation in Post-WWII Neighborhoods in Northwest, Central and Southern Europe. Journal of Urban Affairs 30(1), 63-86.

Dillman, D.A. (2007) Mail and Internet Surveys: The Tailored Design Method. 2nd Ed. Hoboken, NJ: Wiley Inc.

Duany, A., E. Plater-Zyberk, and Speck, J. (2000) Suburban nation: The rise of sprawl and the decline of the American dream. New York: North Point Press.

Edwards, B., and Foley, M.W. (1997) Social capital and the political economy of our discontent. American Behavioral Scientist 40, 669-678.

FalconerAl-Hindi, K and Till, K.D. (2001) (Re)placing the New Urbanism debates: Toward an interdisciplinary research agenda. Urban Geography 22(3), 189-201.

Freeman, L. (2001) The Effects of Sprawl on Neighborhood Social Ties: An Explanatory Analysis. Journal of the American Planning Association 67, 69-77.

Galster, G., Hanson, R., Ratcliffe, M.R, Wolman, H., Coleman. S., and Freihage, J. (2001) Wrestling sprawl to the ground: Defining and measuring an elusive concept. Housing Policy Debate 12, 681-717.

Gans, H. J. (1961) Planning and Social Life: Friendship and Neighbor Relations in Suburban Communities. Journal of the American Institute of Planners 27, 134-140.

Garde, A. J. (2004) New Urbanism as Sustainable Growth? A Supply Side Story and Its Implications for Public Policy. Journal of Planning Education and Research 24, 154-170.

Geolytics, Inc. (2000) Census CD and Maps [GIS data] East Brunswick, NJ.

Grigsby, W., Baratz, M., Galster, G., and MacLennan, D. (1987) The Dynamics of Neighborhood Change and Decline. Progress in Planning 28, 1-76.

Handy, S. Sall, J. F., Weber, D. Maibach, E. and Hollander, M. (2008) Is Support for Traditionally Designed Communities Growing?: Evidence From Two National Surveys. Journal of the American Planning Association 74 (2), 209-221.

Hero, R. E. (2003) Social Capital and Racial Inequality in American. Perspectives on Politics.

$1,113-122$.

Hur, M. Morrow-Jones, H. (2008) Factors that Influence Residents' Satisfaction With Neighborhoods. Environment and Behavior 40, 619-635. 
Jacobs, J. (1961) The Death and Life of Great American Cities. New York: Random House

Kasarda, J. D., and Janowitz, M. (1974) Community attachment in mass society. American Sociological Review 39, 328-339.

Leigh, A. (2006) Trust, Inequality, and Ethnic Heterogeneity. The Economic Record 82, 268-280. (2006b) Does equality lead to fraternity? Economics Letters 93, 121-125.

Leyden, K. M. (2002) Neighborhood Design, Political Participation and Social Capital. Paper presented at the annual meeting of the American Political Science Association, Boston, MA. August.

Lund, H. (2003) Testing the claims of new urbanism: local access, pedestrian travel, and neighboring behaviors, Journal of the American Planning Association, 69 (4), $414-429$. . (2002) Pedestrian Environments and Sense of Community. Journal of Planning Education and Research $21,301-312$.

MacIntyre, S., and Ellaway, A. (2000) Ecological approaches: Rediscovering the role of the physical and social environment. In Social Epidemiology, edited by Lisa F. Berkman and Ichiro Kawachi. New York: Oxford Press.

Mason, S. and Fredericksen, E. (2009). Fostering Neighborhood Viscosity: Does Design Matter? Community Development Journal, Advance Access published July 23, 2009 doi: 10.1093/cdj/bsp037.

Mayo, J. M. (1979) Effects of Street Forms on Suburban Neighboring Behavior. Environment and Behavior 11, $375-397$. (1979b) Suburban Neighboring and the Cul-de-Sac Street. Journal of Architectural Research 7, 22-27.

Nasar, J. L., and Julian, D. A. (1995). The psychological sense of community in the neighborhoods. Journal of the American Planning Association, 61(2), 178-184.

New Urbanism (2010) Creating Livable Sustainable Communities: Urbanism Principles. [online], Available from http://www.newurbanism.org/newurbanism/principles.html

Oliver, J. E. (1999) The Effects of Metropolitan Economic Segregation on Local Civic Participation. American Journal of Political Science 43, 186-212.

Paxton, P. (1999) Is Social Capital Declining in the United States? A Multiple Indicator Assessment. American Journal of Sociology 105, 88-127. 
This is an author-produced, peer-reviewed version of this article. The final, definitive version of this document can be found online at Cities, published by Elsevier. Copyright restrictions may apply. doi: 10.1016/j.cities.2010.07.003

Plas, J. M., and Lewis, S.E. (1996) Environmental Factors and Sense of Community in a Planned Town. American Journal of Community Psychology 24, 109-143.

Podobnik, B. (2002) New Urbanism and the Generation of Social Capital: Evidence from Orenco Station. National Civic Review 91(3), 245-255.

Putnam, R. D. (2000) Bowling Alone: The Collapse and Revival of American Community. New York: Simon and Schuster.

Riger, S. and Lavrakas, P. J. (1981) Community ties: Patterns of Attachment and Social Interaction in Urban Neighborhoods. American Journal of Community Psychology 9, 55-67.

Rohe, W. S (2009) From Local to Global: One Hundred Years of Neighborhood Planning. Journal of the American Planning Association 75 (2) 209-230.

Rothstein, B. and E. Uslaner. (2005) “All for All: Equality and Social Trust”. London: LSE Health and Social Care Discussion Paper Number 15 <http://www.hks.harvard.edu/inequality/ Seminar/Papers/Rothstein1.pdf> accessed December 8, 2007.

Sampson, R. J., Raudenbush, S.W, and Earls, F. (1997) Neighborhoods and Violent Crime: A Multilevel Study of Collective Efficacy. Science 277, 918-924.

Steuteville, R. and Langdon, P. (2003) New Urbanism Comprehensive Report and best Practices Guide. $3^{\text {rd }}$ ed. New York: New Urban News.

Song, Y. (2005) Smart Growth and Urban Development Pattern: A Comparative Study. International Regional Science Review 28, 239-265.

St. Antoine, T. J. (2007) Making Heaven out of Hell: New Urbanism and the Refutation of Suburban Spaces. Southern Communication Journal 72, 127-144.

Sugiyama, T., Thompson, C. W., \& Alves, S. (2009) Association Between Neighborhood Open Space Attributes and Quality of Life for Older People in Britain. Environment and Behavior 41, 3-21.

Talen E. (2003) Measuring Urbanism: Issues in Smart Growth Research. Journal of Urban Studies 8(3), $195-215$. . (1999) Sense of community and neighborhood form: An assessment of the social doctrine of new urbanism. Urban Studies 36, 1361-1379.

U. S. Census Bureau. (2006) American FactFinder 2000. [online], Available from: <http://www.census.gov>. 
This is an author-produced, peer-reviewed version of this article. The final, definitive version of this document can be found online at Cities, published by Elsevier. Copyright restrictions may apply. doi: 10.1016/j.cities.2010.07.003

Yang, Y. (2008) A Tale of Two Cities: Physical Form and Neighborhood Satisfaction in Metropolitan Portland and Charlotte. Journal of the American Planning Association 74 (3) 307-323. 


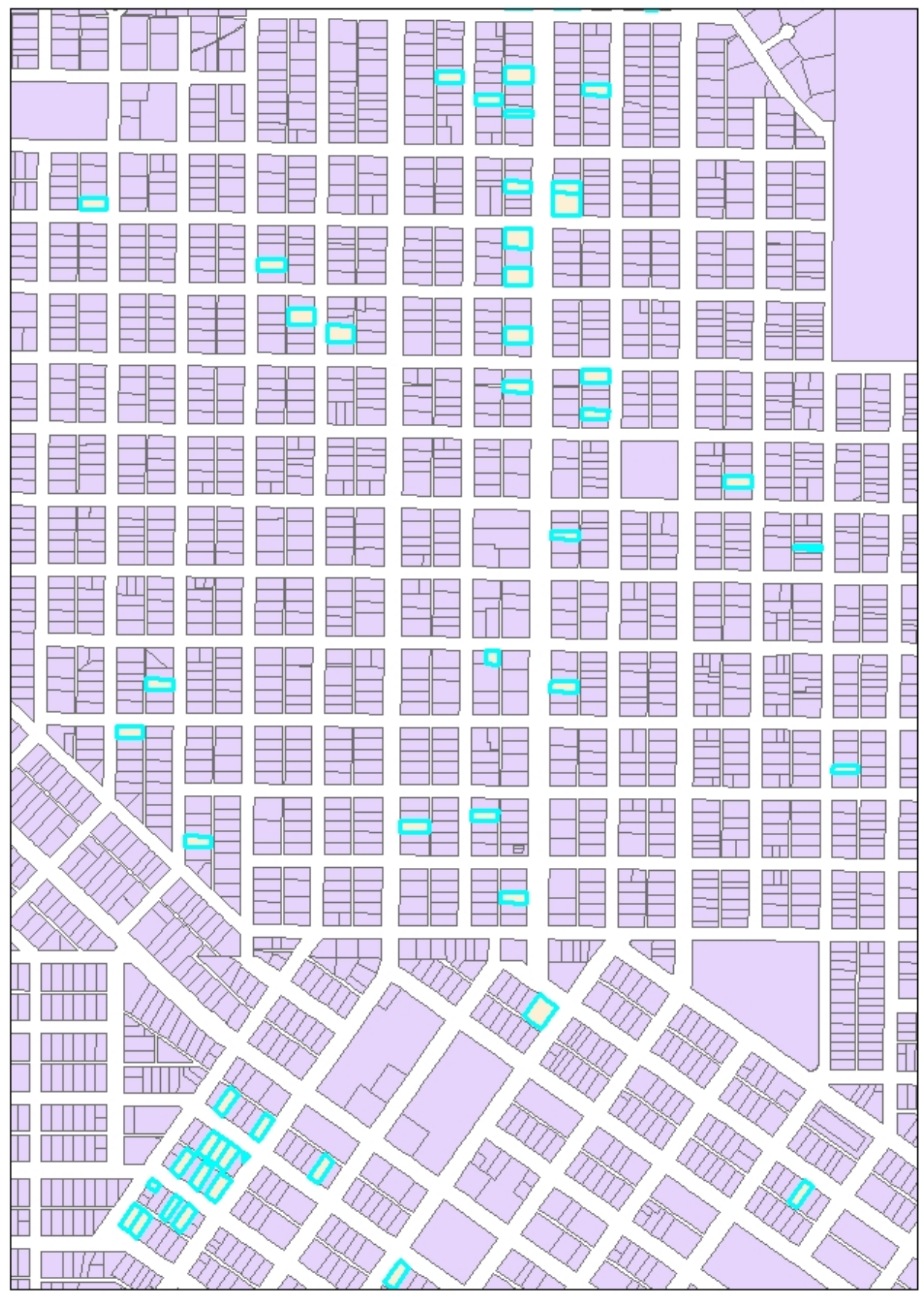

Figure 1. Traditional street design 


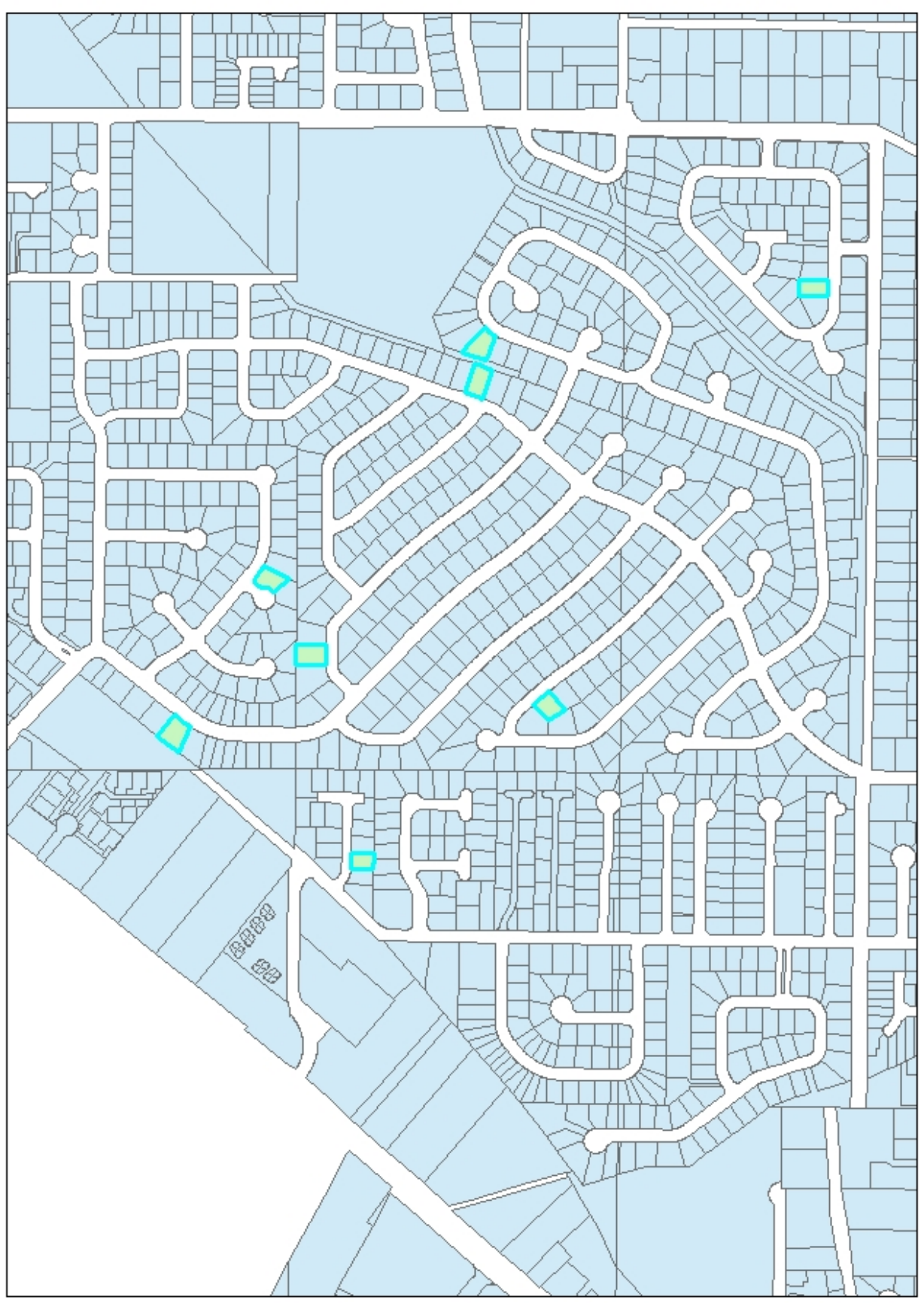

Figure 2. Curvilinear and cul-de-sac street designs 


\section{Table 1}

Means and Standard Deviations of Variables in the Analysis.

\begin{tabular}{|c|c|c|c|}
\hline Variable & Mean & $\begin{array}{l}\text { Standard } \\
\text { Deviation }\end{array}$ & $\mathrm{n}$ \\
\hline \multicolumn{4}{|l|}{ Dependent Variable } \\
\hline Trust & 3.8 & 1.0 & 660 \\
\hline \multicolumn{4}{|l|}{ Independent Variables } \\
\hline Sidewalks & .58 & .49 & 721 \\
\hline Traditional design & .17 & .37 & 721 \\
\hline Curvilinear design & .67 & .47 & 721 \\
\hline Cul-de-sac design & .16 & .37 & 721 \\
\hline Parks or Open Space & .81 & .39 & 707 \\
\hline \multicolumn{4}{|l|}{ Control Variables } \\
\hline \multicolumn{4}{|l|}{ Length of residence in } \\
\hline Years & 13 & 12 & 697 \\
\hline Age in years & 53 & 16 & 698 \\
\hline \multicolumn{4}{|l|}{ Number of children in } \\
\hline Household & .58 & .99 & 707 \\
\hline Female & .61 & .49 & 703 \\
\hline Homeowner & .93 & .26 & 714 \\
\hline Married & .68 & .46 & 701 \\
\hline Bachelor degree or higher & .64 & .48 & 708 \\
\hline Income Inequality in $10,000 \mathrm{~s}$ & .0069 & .0067 & 640 \\
\hline Income Inequality squared in $10,000 \mathrm{~s}$ & .9367 & 2.321 & 640 \\
\hline \multicolumn{4}{|l|}{ Household Income } \\
\hline$\$ 0-\$ 20,000$ & .05 & .21 & 645 \\
\hline$\$ 20,000-\$ 29,000$ & .05 & .22 & 645 \\
\hline$\$ 30,000-\$ 39,000$ & .12 & .32 & 645 \\
\hline$\$ 40,000-\$ 49,000$ & .07 & .26 & 645 \\
\hline$\$ 50,000-\$ 74,999$ & .22 & .42 & 645 \\
\hline$\$ 75,000$ - $\$ 99,999$ & .16 & .37 & 645 \\
\hline$\$ 100,000$ or above & .32 & .47 & 645 \\
\hline
\end{tabular}


This is an author-produced, peer-reviewed version of this article. The final, definitive version of this document can be found online at Cities, published by Elsevier. Copyright restrictions may apply. doi: 10.1016/j.cities.2010.07.003

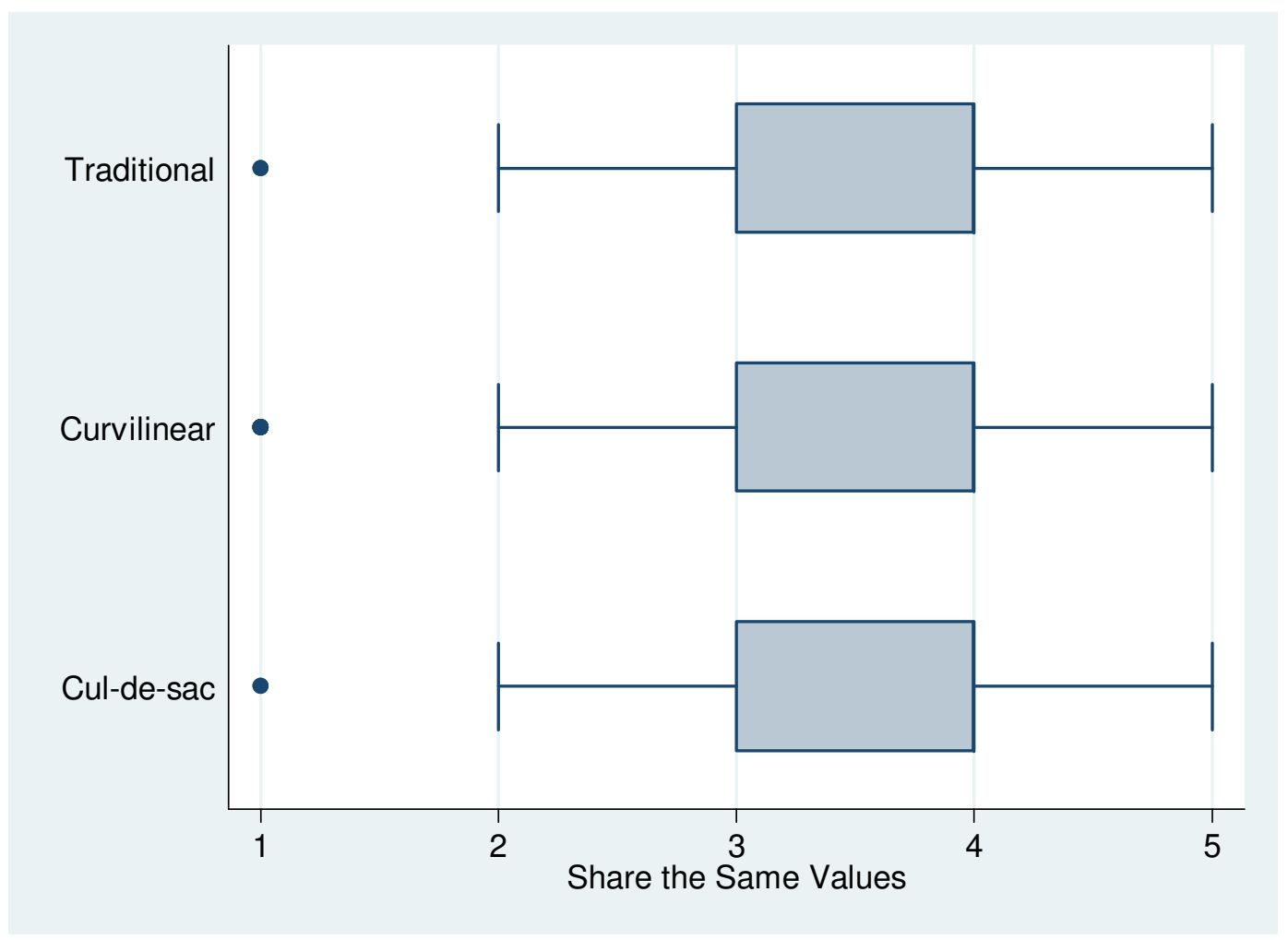

Figure 3. Boxplot of street design on values 
Table 2

Ordered Logistic Regression Estimates of Community Design Variables and Control Factors on Trust with Odds Ratios and the Standard Errors in Parenthesis

\begin{tabular}{|c|c|c|}
\hline Independent Variables & Control Variables on Trust & Full Model \\
\hline Years in Residence & $\begin{array}{l}1.00 \\
(.01)\end{array}$ & $\begin{array}{l}1.00 \\
(.01)\end{array}$ \\
\hline Age & $\begin{array}{r}1.03 * * \\
(.01)\end{array}$ & $\begin{array}{r}1.03 * * \\
(.01)\end{array}$ \\
\hline Number of Children & $1.21^{+}$ & $1.29 *$ \\
\hline living at home & $(.10)$ & $(.11)$ \\
\hline Female & $\begin{array}{c}1.48^{*} \\
(.18)\end{array}$ & $\begin{array}{r}1.53^{*} \\
(.18)\end{array}$ \\
\hline Homeowner & $\begin{array}{r}-2.80 * * \\
(.36)\end{array}$ & $\begin{array}{r}-2.88 * * \\
(.36)\end{array}$ \\
\hline Married & $\begin{array}{r}-1.35 \\
(.24)\end{array}$ & $\begin{array}{r}-1.18 \\
(.25)\end{array}$ \\
\hline $\begin{array}{l}\text { Bachelor's degree } \\
\text { or higher }\end{array}$ & $\begin{array}{l}1.18 \\
(.20)\end{array}$ & $\begin{array}{l}1.17 \\
(.20)\end{array}$ \\
\hline Income Inequality in & 3.55 & 1.60 \\
\hline $10,000 \mathrm{~s}$ & (58.26) & $(59.58)$ \\
\hline $\begin{array}{l}\text { Income Inequality squared } \\
\text { in } 10,000 \text { 's }\end{array}$ & $\begin{array}{r}-1.71 \\
(.33)\end{array}$ & $\begin{array}{r}-1.85^{+} \\
(.34)\end{array}$ \\
\hline Household Income $\mathrm{a}^{\mathrm{a}}$ & & \\
\hline$\$ 20,000-\$ 29,999$ & $\begin{array}{r}1.10 \\
(. .41)\end{array}$ & $\begin{array}{l}1.13 \\
(.42)\end{array}$ \\
\hline$\$ 30,000$ - $\$ 39,999$ & $\begin{array}{r}-1.36 \\
(.40)\end{array}$ & $\begin{array}{r}-1.32 \\
(.43)\end{array}$ \\
\hline$\$ 40,000-\$ 49,999$ & $\begin{array}{r}-1.35 \\
(.45)\end{array}$ & $\begin{array}{r}-1.51 \\
(.46)\end{array}$ \\
\hline$\$ 50,000-\$ 74,999$ & $\begin{array}{r}-1.17 \\
(.38)\end{array}$ & $\begin{array}{r}-1.22 \\
(.40)\end{array}$ \\
\hline$\$ 75,000-\$ 100,000$ & $\begin{array}{l}1.33 \\
(.44)\end{array}$ & $\begin{array}{l}1.16 \\
(.47)\end{array}$ \\
\hline$\$ 100,000$ or more & $\begin{array}{l}1.57 \\
(.46)\end{array}$ & $\begin{array}{l}1.36 \\
(.48)\end{array}$ \\
\hline Street Design ${ }^{b}$ & & \\
\hline Traditional & & $\begin{array}{l}1.15 \\
(.26)\end{array}$ \\
\hline Cul-de-sac & & $\begin{array}{r}1.75^{*} \\
(.26)\end{array}$ \\
\hline Sidewalks & & $\begin{array}{r}1.63 * * \\
(.19)\end{array}$ \\
\hline Parks or Open & & $2.07 * *$ \\
\hline Space & & $(.26)$ \\
\hline Pseudo R 2 & .04 & .06 \\
\hline LR Chi2 & $48.45 * *$ & $71.38 * *$ \\
\hline $\mathrm{N}$ & 460 & 449 \\
\hline
\end{tabular}

Notes. ${ }^{\text {a }}$ The reference category for Household Income is "less than $\$ 20,000$ "

b The reference category for Street Design in this table is "Curvilinear".

$+\mathrm{p} \leq .05$ one-tailed; $* \mathrm{p} \leq .05$ two-tailed; $* * \mathrm{p} \leq .01$ two-tailed 
Table 3

T-test Results for Unequal Variance and Descriptive Statistics for Variables by Street Design

\begin{tabular}{|c|c|c|c|c|c|c|c|}
\hline Variable & & Traditional & Curvilinear & Traditional & $\begin{array}{l}\text { Cul-de- } \\
\text { sac }\end{array}$ & Curvilinear & $\begin{array}{l}\text { Cul-de- } \\
\text { sac }\end{array}$ \\
\hline \multirow[t]{4}{*}{ Trust } & $M^{a}$ & 3.74 & 3.78 & $3.74 * *$ & $4.02 * *$ & $3.78 * *$ & $4.02 * *$ \\
\hline & SD & .96 & 1.03 & .96 & .79 & 1.03 & .79 \\
\hline & $\mathrm{n}$ & 107 & 441 & 107 & 112 & 441 & 112 \\
\hline & M & $51,518 * *$ & $64,419 * *$ & $51,518 * *$ & $73,738 * *$ & $64,419 * *$ & $73,738 * *$ \\
\hline \multirow[t]{2}{*}{ Income } & SD & 29,999 & 29,358 & 29,999 & 28,316 & 29,358 & 28,316 \\
\hline & $\mathrm{n}$ & 112 & 430 & 112 & 103 & 430 & 103 \\
\hline Income & M & $2.26 * *$ & $.7 * *$ & $2.26 * *$ & $.47 * *$ & $.7 * *$ & $.47 * *$ \\
\hline Inequality & SD & 4.86 & .05 & 4.86 & .60 & .05 & .60 \\
\hline $\begin{array}{l}\text { index in } \\
10,000 \text { 's }\end{array}$ & $\mathrm{n}$ & 112 & 426 & 112 & 102 & 426 & 102 \\
\hline \multirow[t]{3}{*}{ Sidewalks } & M & $.81 * *$ & $.50 * *$ & $.81 * *$ & $.67 * *$ & $.50 * *$ & $.67 * *$ \\
\hline & SD & .39 & .50 & .39 & .47 & .50 & .47 \\
\hline & $\mathrm{n}$ & 121 & 482 & 121 & 118 & 482 & 118 \\
\hline \multirow[t]{3}{*}{ Parks } & M & $.92 * *$ & $.79 * *$ & $.92 * *$ & $.78 * *$ & .79 & .78 \\
\hline & SD & .27 & .40 & .27 & .42 & .40 & .42 \\
\hline & $\mathrm{n}$ & 118 & 471 & 118 & 118 & 471 & 118 \\
\hline
\end{tabular}

Note. ${ }^{\mathrm{a}} \mathrm{M}=$ mean; $\mathrm{SD}=$ standard deviation; $\mathrm{n}=$ number of observations $* * \mathrm{p}<.01$

Source: Author's calculations from Neighborhood Survey 2008. 